\title{
O PROGRAMA DE MANEJO DIFERENCIADO E RECICLAGEM DE RESÍDUOS DA PREFEITURA DE BELO HORIZONTE
}

\author{
Renato de Oliveira Moraes \\ Doutor em Administração pela Universidade de São Paulo - USP \\ Professor do Mestrado Profissionalizante em Economia de Empresa da \\ Universidade de São Paulo - USP \\ remo@usp.br \\ Priscila Maria Santiago Pereira \\ Mestre em Enga. de Construção Civil e Urbana pela Escola Politécnica da \\ Universidade de São Paulo - POLI/USP \\ prisicla.santiago@yahoo.com.br
}

\section{RESUMO}

Em consequência do grande volume de resíduos gerados e visando a recuperação ambiental, a empresa municipal responsável pela limpeza urbana de Belo Horizonte implantou, a partir de 1993, o Programa de Manejo Diferenciado e Reciclagem de Resíduos, buscando devolvê-los como matéria-prima para o setor produtivo, ou de forma a não agredir o meio ambiente. Foram criadas, também, unidades de reciclagem de entulho. Atualmente, encontram-se em operação três dessas unidades, localizadas em bairros distintos da cidade. Pretende-se, por meio deste artigo, apresentar a implantação Programa para a Correção das Deposições e Reciclagem de Resíduos da Construção Civil em Belo Horizonte - implantado com o objetivo de corrigir os problemas ambientais urbanos gerados pela deposição indiscriminada e clandestina de resíduos de construção nas vias urbanas, um panorama da situação atual do gerenciamento de resíduo de construção civil no município, como funcionam as Unidades de Recebimento de Pequenos Volumes e a importância que isto representa numa abordagem mais atual de gerenciamento integrado de resíduos sólidos municipais, cujas principais recomendações são: a prevenção; a reutilização; a recuperação; a reciclagem; o tratamento; a disposição final; a recuperação de áreas degradadas e a ampliação da cobertura de serviços ligados aos resíduos.

Palavras-chave: Gerenciamento integrado de resíduos; Resíduo da construção civil; Resíduo urbano.

\section{UNIQUE PROGRAM MANAGEMENT AND RECYCLING WASTE OF CITY OF BELO HORIZONTE}

\begin{abstract}
As a result of the great volume of generated waste, the municipal company responsible for the urban cleanliness of Belo Horizonte, aimed at ambient recovery by implanting, from 1993, the Program of Differentiated Handling and Recycling of Wastes, searching to return them as raw material for the productive sector, or of a form not to attack the environment. They had been servants as well as units of rubbish recycling and currently three of these units are in operation, located in distinct quarters of the city. This article presents the implantation of Program for Correction of Depositions and Recycling of Construction Civil Wastes in Belo Horizonte. The objective of this program is to correct problems ambient urban generated for deposition indiscriminate and clandestine of waste of construction in urban ways. The current handling of waste management of construction civil in city, are the Small Volumes Receiving Units and the importance function that this represents in a more current boarding of integrated management of municipal solids wastes, where the main recommendations are: the prevention; the reuse; the recovery; the recycling; the treatment; the final disposal; the recovery of degraded areas, and the magnifying of the covering of on services to the wastes.
\end{abstract}

Keywords: Construction Civil Wastes; Integrated Waste Management; Urban Waste. 


\section{INTRODUÇÃO}

A preocupação com o aumento na geração de resíduos vem crescendo nas últimas décadas. O consumo cada vez maior das sociedades acarreta a destruição dos recursos naturais, e os bens acabam por se transformar em resíduo, mais cedo ou mais tarde, em quantidades crescentes com as quais não se sabe o que fazer (Barros e Möller, 1995). Segundo o Manual editado pelo Instituto Brasileiro de Administração Municipal (IBAM) (2001), a indústria da construção civil é a que mais explora recursos naturais e também é a que mais gera resíduos, devido à tecnologia construtiva que normalmente é aplicada na execução de novas edificações. Os resíduos da construção e demolição (RCD) são um dos responsáveis pelo esgotamento de áreas de aterro em cidades de médio e grande porte, uma vez que correspondem a mais de 50\% dos resíduos sólidos urbanos. São eles também, responsáveis por altos custos econômicos e ambientais nessas cidades, em razão das disposições irregulares (Ângulo, Zordan e John, 2001), que acabam gerando degradação da qualidade de vida, com a redução da eficiência dos sistemas de tráfego e de drenagem.

Conforme dados da Superintendência de Limpeza Urbana - SLU, a geração média de resíduos urbanos, em Belo Horizonte, é de 4 mil t/dia. Desse total, 41\% correspondem aos resíduos da construção civil, não se considerando a quantidade de resíduos depositados nos aterros de inertes, sobre os quais não há dados disponíveis.

Embora a responsabilidade pela coleta e disposição de entulho (RCD) seja de quem o produz, cabe ao serviço de limpeza pública a disposição sanitariamente adequada deste material (Barros e Möller, 1995). Em Belo Horizonte, esses resíduos são classificados como "resíduos especiais" de acordo com o Regulamento de Limpeza Urbana, não sendo, portanto, responsabilidade do município a sua coleta e destinação final. A SLU, no entanto, devido ao alto percentual de entulho presente na massa de resíduos total do município, optou por executar essa coleta com empresas privadas, destinando o resíduo no aterro sanitário (Fiúza, 2001).

No Gerenciamento Integrado de Resíduos Sólidos (Ibam, 2001) pressupõe-se o envolvimento de diferentes órgãos da administração pública e da sociedade civil com o propósito de realizar a limpeza urbana, a coleta, o tratamento e a disposição final do lixo, elevando assim a qualidade de vida da população e promovendo o asseio da cidade.

Neste contexto, pretende-se, por meio deste artigo, descrever o sistema de gerenciamento de resíduos de construção implantado na cidade de Belo Horizonte a partir de 1993. A análise das dificuldades e dos resultados alcançados ao longo desse período apresenta alguns aspectos que podem ser destacados como desafios a serem vencidos para uma gestão mais sustentável de resíduos de construção no município.

\section{METODOLOGIA}

A metodologia utilizada para descrição e análise do Programa para a Correção das Deposições e Reciclagem de Resíduos da Construção Civil contou com uma análise documental de acervos relativos à história da limpeza urbana da Superintendência e à implantação do modelo de gestão ora estudado. Nesse procedimento de pesquisa, buscou-se identificar as possíveis relações entre as práticas de gestão ambiental adotadas pelo governo municipal e as posturas ambientais e pressões que estavam ocorrendo no país e no mundo naquele momento.

Foi feito um levantamento dos dados disponíveis no acervo técnico da SLU em relação às quantidades de resíduos de construção aterrados e reciclados, além de entrevista no Departamento de Projetos Especiais (responsável pelo gerenciamento de RCC) para esclarecimentos adicionais que vieram contribuir para uma melhor visualização da situação atual do gerenciamento de resíduos de construção civil no município. 


\subsection{GERENCIAMENTO DE RESÍDUOS SÓLIDOS NO MUNICÍPIO - ANTECEDENTES}

Nos anos 1970, as políticas federais de controle de resíduos sólidos, buscavam estabelecer normas referentes à forma mais adequada de coleta e disposição do material descartado. Em Belo Horizonte, até essa década, os resíduos do município eram depositados pela Prefeitura nos mesmos locais usados desde a construção da cidade no século XIX (Amaral, 2006), situação só alterada após duas tragédias ocorridas no local (dois deslizamentos ocorridos em 1971 e 1972, provocando a morte de 19 pessoas no total). Estas catástrofes induziram uma tomada de decisão por parte das autoridades municipais. Ainda em 1972, foi elaborado o primeiro Plano Diretor de Limpeza Urbana da cidade e indicadas opções para a implantação de novas áreas destinadas ao tratamento e à disposição final do lixo da cidade (Amaral, 2006). E em 1973 foi criada a Superintendência de Limpeza Urbana - SLU - autarquia municipal responsável pelo gerenciamento de resíduos sólidos na Capital.

Em 1978, a Lei 2968, aprovou o Regulamento de Limpeza Urbana de Belo Horizonte. A maior preocupação em relação os resíduos de construção, na época, refere-se a não permitir a ocupação de qualquer parte do passeio, da via ou logradouro público com resíduos, materiais de construção e/ou demolição, além do alinhamento de tapume. Quanto aos resíduos "inservíveis", deveriam ser removidos para os locais de disposição final indicados pela SLU.

Em junho de 1992, na Conferência das Nações Unidas sobre o Meio Ambiente e Desenvolvimento, foi estabelecida a Agenda 21, que no capítulo 21, seção II - Buscando soluções para o problema do lixo sólido, aponta algumas propostas para o equacionamento dos problemas dos resíduos sólidos, tendo como principais recomendações: a prevenção pela redução do volume na fonte; a reutilização; a recuperação; a reciclagem; o tratamento; a disposição final; a recuperação de áreas degradadas e a ampliação da cobertura de serviços ligados aos resíduos (Brollo e Silva, 2001).

Neste contexto, o gerenciamento de resíduos no município de Belo Horizonte passou a estabelecer princípios que garantissem consistência com o desenvolvimento sustentável (SLU, s.d.). E a partir de 1993, a SLU implantou, em Belo Horizonte, um sistema de manejo diferenciado de tratamento dos resíduos sólidos gerados no município (PINTO, 1999), buscando devolvê-los como matéria-prima para o setor produtivo, ou de forma a não agredir o meio ambiente: o Programa de Manejo Diferenciado e Reciclagem de Resíduos.

Com relação ao resíduo de construção civil, foi implantado o Programa para a Correção das Deposições e Reciclagem de Resíduos da Construção Civil, com o objetivo de corrigir os problemas ambientais urbanos gerados pela deposição indiscriminada e clandestina de resíduos de construção na malha urbana. Este projeto visava não só a criação de mecanismos apropriados que incentivassem a deposição correta dos resíduos como também a recuperação das áreas urbanas degradadas por meio de mecanismos fiscalizatórios e da utilização, nessas mesmas áreas e adjacências, de componentes construtivos e de urbanização, fabricados com base nos insumos obtidos do entulho reciclado (Relatório SLU, s.d.).

Um diagnóstico realizado entre março e junho de 1993 quantificou a geração de resíduos de construção na época (3.000 t/dia de resíduos provenientes da construção civil), estimou em 900 t/dia a quantidade de resíduos com características recicláveis e foram detectados 134 pontos de deposição clandestina (Relatório SLU, s.d.).

O programa implementado contemplava a implantação de três redes de áreas para recuperação e processamento de resíduos e o desenvolvimento de três subprogramas de ação.

O programa salientava a importância da localização geográfica das instalações, que devem estar mais próximas das regiões geradoras de resíduos para otimizar o fluxo de transporte de entulho na área urbana e facilitar a correção de práticas errôneas de deposição verificadas junto aos 
mesmos locais de maior geração e de também contarem com a adesão da população do entorno ao programa.

A implantação do Projeto Piloto na região oeste do município (Bairro Estoril) ocorreu entre meados de 1994 e início de 1995. Os equipamentos utilizados na reciclagem têm origem nos equipamentos de mineração e, para sua instalação no espaço urbano, foram considerados, especialmente, a contenção dos ruídos gerados e a contenção do material particulado.

Com o funcionamento bem-sucedido da primeira estação, a implantação da segunda, que já estava prevista, aconteceu em razão da demanda da sociedade por esse serviço. Assim, em 1996, foi implantada a Estação de Reciclagem de Entulho Pampulha. E em 2006 foi implantada a terceira Estação de Reciclagem de Entulho, na Central de Tratamento de Resíduos Sólidos (CTRS /BR 040), situado na Rodovia BR 040, bairro Jardim Filadélfia.

\section{GERENCIAMENTO DE RCD EM BELO HORIZONTE - SITUAÇÃO EM 2007}

Em Belo Horizonte, o planejamento e operacionalização da coleta de resíduos de construção de grandes geradores vêm sendo feitos pelo estabelecimento de um sistema de coleta desse material por empresas especializadas. Mediante contrato com a Prefeitura, essas empresas têm permissão para explorar o serviço de aluguel de caçambas estacionárias de $5 \mathrm{~m}^{3}$ em geral (que devem ser exclusivas para resíduos de construção), cobrando do munícipe um valor referente ao aluguel e transporte adequado desse material até o aterro sanitário ou outro local autorizado. Os resíduos são, então, encaminhados para o aterro sanitário municipal ou para uma das áreas autorizadas pelo município para destinação dos resíduos de construção nas regiões Norte e Nordeste. Esses locais, chamados de bota-foras autorizados, são, na verdade, aterros executados com resíduos da construção civil, ou seja, terra e entulho.

Os bota-foras, normalmente, constituem-se de terrenos irregulares ou erodidos que passam a ser reconformados topograficamente por meio do aterramento de materiais inertes. A autorização para implantação de bota-foras de materiais provenientes de desaterro e entulho é concedida pela Secretaria Municipal de Meio Ambiente em conjunto com a Superintendência de Desenvolvimento a Capital, responsável por verificar os projetos de drenagem e de execução da obra de aterro da área. São locais essenciais na dinâmica da cidade e funcionam como alternativa complementar à reciclagem e à disposição no aterro sanitário, principalmente em relação aos grandes volumes de solo natural, provenientes de desaterros (Lima e Chenna, 2000).

O número de áreas disponíveis, entretanto, vem diminuindo: em 1993 havia 15 áreas autorizadas; em 1998, havia cinco áreas de portes variados e em 2007 apenas três áreas autorizadas que, segundo a SLU, estão chegando ao limite de suas capacidades. Estão sendo feitos estudos na SLU para viabilizar novas áreas de aterros de inertes em Belo Horizonte ou na região metropolitana.

Para os pequenos geradores de resíduos de construção, a SLU vem aumentando a implantação de Unidades de Recebimento de Pequenos Volumes (URPVs). Já foram implantadas 29 áreas para entrega voluntária de resíduos sólidos espalhadas entre as nove regionais do município, o que contribui para que os pontos de deposição clandestinos não tivessem um crescimento maior. As URPVs são locais autorizados pela Prefeitura para receber até o limite diário de $2 \mathrm{~m}^{3}$ por obra, os seguintes materiais: madeira, terra, metais, podas, concreto, gesso, tijolo e pneus. O material depositado é separado e encaminhado para uma das Estações de Reciclagem. Existe a previsão de serem instaladas outras URPVs na cidade, porém percebe-se hoje, na SLU, que tal equipamento não é o mais adequado para utilização em áreas de favelas (onde há uma grande concentração de pequenas construções e de deposições clandestinas) e estuda-se uma nova abordagem para solucionar o problema.

Os carroceiros, até então considerados pelo poder público como degradadores do meio ambiente por depositarem o material coletado, muitas vezes, de forma clandestina, foram incorporados no programa de reciclagem de entulhos em 1997 (Silva e Brito, 2006). Passaram a

Revista de Gestão Social e Ambiental - RGSA, São Paulo, v. 6, n. 1, p. 117-126, jan./abril 2012. 
atuar na rede de coleta como prestadores de serviço de transporte de entulhos (oriundos de pequenas construções e reformas), evitando assim o depósito desse material em locais de deposição clandestina. Por meio do "Disque-carroça" (telefone da Prefeitura destinado exclusivamente para a contratação de coleta de entulho por meio de carroceiros), o pequeno gerador encaminha o material até a URPV, onde é feita a separação de acordo com sua natureza em caçambas próprias. O material também pode ser entregue diretamente pelo pequeno gerador, desde que não exceda a quantidade especificada. O material recebido nas URPVs é encaminhado para as Unidades de Reciclagem de Entulho ou para o aterro sanitário, quando não há possibilidade de reciclagem.

As três Unidades de Reciclagem de Entulho, localizadas nos bairros Estoril e Pampulha (com capacidade de processamento de 120 e 240 t/dia) e na Central de Tratamento de Resíduos Sólidos (CTRS) processaram, no mês de março de 2007, 8.105 toneladas de material.

A Figura 1 apresenta a quantidade de resíduo gerado no município, quantidade de resíduo de construção civil e quantidade de material reciclado a partir de 1996. Os dados foram baseados na geração de resíduos apresentados nos relatórios da SLU nos meses de dezembro de cada ano, exceto no ano de 2007, com informações referentes a março.

Gráfico 1: Geração e reciclagem de RCC em Belo Horizonte (1993 - 2007).

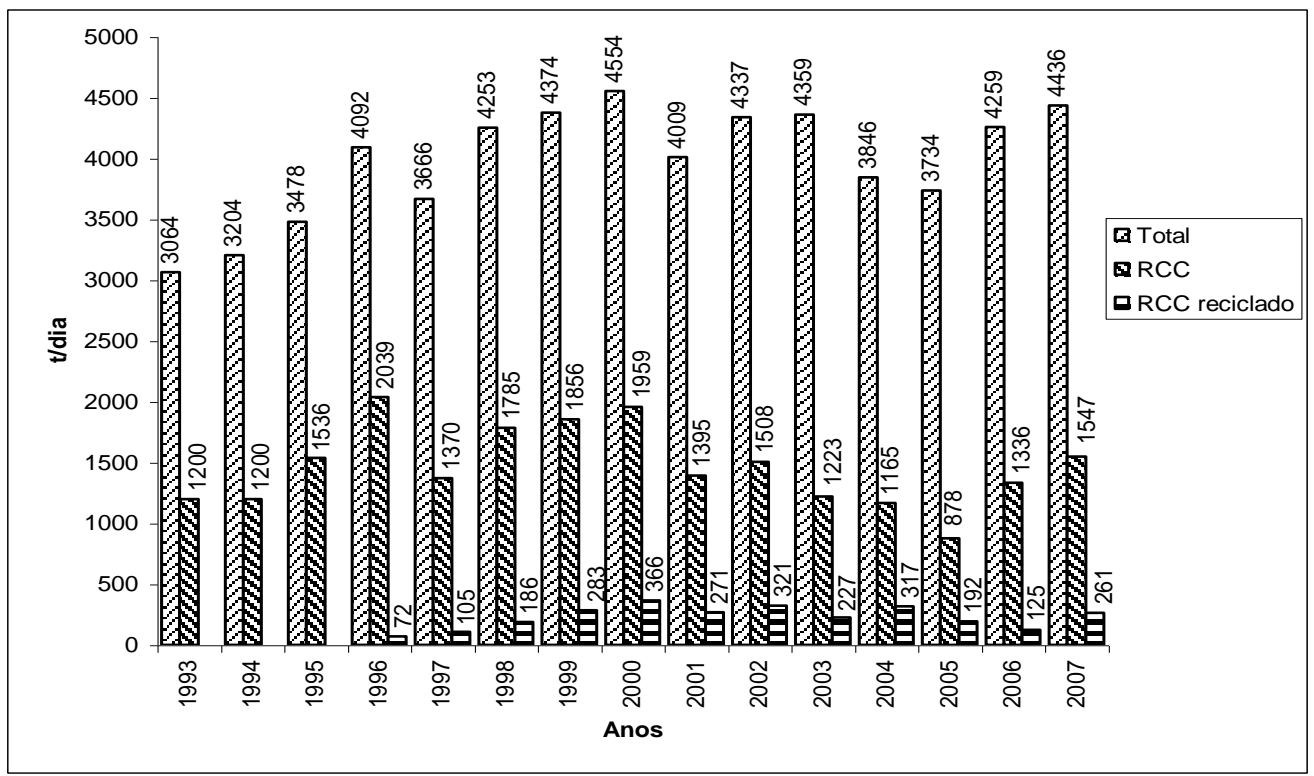

Fonte: Relatórios de Atividades da Limpeza Urbana de 1993 a 2007.

Há variações mensais na geração de resíduo devido, principalmente, à dinâmica da indústria de construção civil. O trabalho com a média anual, que seria o tratamento ideal nesse tipo de análise, não foi possível por não haver dados anuais médios consolidados de todos os anos.

As Estações de Reciclagem são compostas por: uma edificação de apoio administrativo; guarita; portão e cercamento da área; áreas para estocagem de material recebido e processado; estrutura de apoio do equipamento britador; conjunto britador (moinho de impacto).

As Estações de Reciclagem têm por objetivo transformar os materiais de construção civil em agregados reciclados, que podem substituir a brita e a areia em elementos da construção civil que não tenham função estrutural. Essas unidades recebem resíduos que apresentam, no máximo, 10\% de outros materiais (plástico, papel, metal etc) e ausência de terra, matéria orgânica, gesso e amianto. O resíduo reciclável contém, essencialmente materiais cerâmicos, peças de concreto e argamassa, areia, brita etc (Lima e Chenna, 2000).

O processo de reciclagem é composto das seguintes etapas: 
- Recepção - o material é inspecionado e, se aceito, é britado e classificado, de acordo com sua composição. A parcela rejeitada vai para o aterro sanitário.

- Seleção: o material é separado manualmente dos rejeitos que, se forem recicláveis ou reaproveitáveis, são devidamente destinados.

- Operação de britagem: os resíduos são levados até o alimentador vibratório do britador, depois para a calha simples e daí para o transportador de correia. Após a britagem, há eliminação de pequenas partículas metálicas ferruginosas pela ação de um eletroimã.

- Estocagem de pilhas; o material reciclado é acumulado sob o transportador de correia.

- Expedição.

O entulho reciclado pode ser usado como base e sub-base de rodovias, agregado graúdo na execução de estruturas de edifícios, e obras de arte de concreto armado e em peças pré-moldadas. Em Belo Horizonte, o principal uso dos materiais reciclados é em pavimentação e manutenção de vias urbanas, em serviços como preparação de vias internas e células no Aterro Municipal, em substituição ao solo nobre anteriormente importado de outros locais e em obras de infraestrutura em vilas e favelas.

Outra utilização do resíduo de construção pode ser demonstrada por meio do projeto Ecobloco, projeto de inclusão social de pessoas de rua. Este projeto surgiu de um trabalho escolar realizado por três alunos do Sebrae e recebeu o apoio da Prefeitura por intermédio da Secretaria de Assistência Social (Silva e Brito, 2006).

Esse trabalho focava a utilização de agregado reciclado da construção civil como matériaprima para produção de artefatos de concreto. A Ecobloco que foi inaugurada em junho de 2004 e encontra-se instalada na Estação de Reciclagem Estoril, sendo gerenciada pelos próprios trabalhadores, capacitados em gestão de negócios. A fábrica trabalha com a confecção de blocos de concreto, considerados o carro-chefe da produção, para atender à demanda crescente de mercado. Entretanto, há a intenção de se fabricarem outros artefatos de concreto. A matéria-prima empregada é proveniente da reciclagem do material coletado pela rede receptora. Os blocos fabricados são vendidos para as casas de material de construção localizadas no entorno da Estação de Reciclagem Estoril e revendidas. A qualidade desses artefatos fabricados é garantida por parcerias com uma empresa especializada que tem apoiado o projeto Ecobloco e com a Escola de Engenharia da Universidade Federal de Minas Gerais - UFMG (por meio dos trabalhos de ensaios desse material e pesquisas para a melhoria da qualidade dos blocos fabricados).

Na Estação de Reciclagem de Entulhos da Pampulha também são fabricados blocos de concreto em pequenas quantidades, mas segundo a SLU, há previsão de instalação de uma segunda fábrica Ecoblocos nesse local. A parcela rejeitada na reciclagem é encaminhada para o aterro sanitário municipal.

Visando a recuperação de áreas degradadas pela deposição irregular de resíduos, foi implantado o Programa Ponto Verde, Ponto Limpo, transformando esses locais em espaços de lazer para a população. Desde sua implantação, 200 pontos clandestinos de depósito de resíduos foram transformados em Pontos Verdes/Pontos Limpos. Entretanto, em estudo realizado em setembro de 2006, foram identificados 144 pontos de deposição clandestina na cidade, iniciados entre 1999 e 2004. A tabela 1 apresenta a distribuição dos resíduos urbanos de Belo Horizonte, e os dados sobre aos resíduos destinados à reciclagem no município encontram-se na tabela 2.

É importante ressaltar que os resíduos de construção civil da Tabela 1 referem-se apenas aos materiais destinados na CTRS para aterragem (e efetivamente pagos). Os resíduos (especialmente terra) dispostos nos bota-fora autorizados somam, segundo estimativa da SLU, uma quantidade igual àquela destinada ao aterro sanitário.

Em 2003, o Código de Posturas do Município (Lei 861 de 14/07/2003) forneceu novas orientações para resíduos de construção, proibindo a utilização de logradouro público, de parque, de margens de curso d'água e de área verde como bota-fora ou áreas de empréstimo. E em 2006, a Lei

Revista de Gestão Social e Ambiental - RGSA, São Paulo, v. 6, n. 1, p. 117-126, jan./abril 2012. 
9193 de 19/04/2006 dispôs sobre a implantação de usina de reciclagem de resíduos sólidos. A lei autoriza a implantação de usinas de reciclagem de resíduos de construção civil e de resíduos de poda de árvores em cada administração regional; incentiva a implantação de centros de serviços para produção de agregados provenientes de materiais recicláveis do entulho da construção civil e determina que cabe ao Poder Executivo, por meio de programas e parcerias com agentes privados envolvidos na indústria da construção, incentivar o uso de materiais recicláveis na construção de casas populares e obras públicas.

Tabela 1: Composição dos resíduos sólidos de Belo Horizonte destinados à aterragem.

\begin{tabular}{|l|l|l|}
\hline Procedência & $\begin{array}{l}\text { Geração } \\
\text { média (t/dia) }\end{array}$ & $\begin{array}{l}\text { Percentual } \\
\text { (t/mês) }\end{array}$ \\
\hline Resíduo domiciliar ou comercial & $1.420,42$ & $32,02 \%$ \\
\hline Resíduos de coletas diferenciadas & $\mathbf{6 0 1 , 6 8}$ & $\mathbf{1 3 , 5 6 \%}$ \\
\hline Resíduos Domiciliares de Vilas, Favelas e locais de difícil acesso & 99,00 & $2,23 \%$ \\
\hline Resíduos Coleta Manual Deposição Clandestina & 117,80 & $2,66 \%$ \\
\hline Resíduos Coleta Mecânica Deposição Clandestina. & 384,88 & $8,68 \%$ \\
\hline Resíduo Domiciliar recolhido por caçambas (exceto URPV) & 31,76 & $0,72 \%$ \\
\hline Resíduo Unidades de Saúde & 39,08 & $0,88 \%$ \\
\hline Resíduos Públicos (varrição, poda capina, barro e campanha Dengue) & 415,27 & $9,36 \%$ \\
\hline Resíduos Particulares (exceto RCC) & 66,37 & $1,50 \%$ \\
\hline Resíduo da construção civil - RCC ${ }^{(1)}$ & $1.546,62$ & $34,87 \%$ \\
\hline Limpeza geral da CTRS & 30,49 & $0,69 \%$ \\
\hline TOTAL 1 & $\mathbf{4 . 1 5 1 , 6 8}$ & $\mathbf{9 3 , 6 9 \%}$ \\
\hline
\end{tabular}

Fonte: Relatório de Atividades de Limpeza Urbana, SMLU/SLU/GERLU, Março de 2007.

${ }^{(1)}$ Da geração de entulho destinado ao aterro sanitário, parte é utilizada no manejo de resíduo como material de cobertura e parte é utilizada para revestimento das pistas do próprio aterro.

Tabela 2: Composição dos resíduos sólidos de Belo Horizonte destinados à reciclagem.

\begin{tabular}{|l|l|l|}
\hline Procedência & $\begin{array}{l}\text { Geração média } \\
\text { (t/dia) }\end{array}$ & $\begin{array}{l}\text { Percentual } \\
\text { (t/mês) }\end{array}$ \\
\hline Resíduos de coleta seletiva de Orgânicos em Feiras e Sacolões & 4,36 & $0,10 \%$ \\
\hline Resíduos da Construção Civil & $\mathbf{2 6 1 , 4 5}$ & $\mathbf{5 , 8 9 \%}$ \\
\hline - CTRS/BR-040 & 65,50 & $1,48 \%$ \\
\hline - Estoril & 70,34 & $1,59 \%$ \\
\hline - Pampulha & 125,61 & $2,83 \%$ \\
\hline Resíduos de Coleta Seletiva de Materiais Reciclados & 18,50 & $0,42 \%$ \\
\hline TOTAL 2 & $\mathbf{2 8 4 , 3 1}$ & $\mathbf{6 , 4 1 \%}$ \\
\hline TOTAL (1+2) & $\mathbf{4 . 4 3 5 , 9 9}$ & $\mathbf{1 0 0 , 0 0 \%}$ \\
\hline
\end{tabular}

Fonte: Relatório de Atividades de Limpeza Urbana, SMLU/SLU/GERLU, Março de 20007.

A tabela 3 apresenta a rede estruturada pela SLU para o gerenciamento de resíduo de construção civil em Belo Horizonte, distribuída nas 9 regiões administrativas do município.

Tabela 3: Rede para gerenciamento de resíduo de construção em Belo Horizonte.

\begin{tabular}{|l|c|c|c|c|}
\hline \multicolumn{1}{|c|}{$\begin{array}{c}\text { Regiões } \\
\text { Administrativas }\end{array}$} & URPV & $\begin{array}{c}\text { Aterro } \\
\text { Sanitário }\end{array}$ & $\begin{array}{c}\text { Usinas de Reciclagem } \\
\text { de RCC }\end{array}$ & $\begin{array}{c}\text { Bota-fora } \\
\text { autorizado }\end{array}$ \\
\hline Oeste & 4 & & 1 & \\
\hline Pampulha & 4 & & 1 & \\
\hline Noroeste & 3 & 1 & 1 & \\
\hline Centro-Sul & 1 & & & \\
\hline Barreiro & 5 & & & \\
\hline
\end{tabular}




\begin{tabular}{|l|c|c|c|c|}
\hline Leste & 2 & & & \\
\hline Nordeste & 3 & & & 2 \\
\hline Norte & 3 & & & 1 \\
\hline Venda Nova & 4 & & & \\
\hline Total & 29 & 1 & 3 & 3 \\
\hline
\end{tabular}

\section{DIFICULDADES E RESULTADOS ALCANÇADOS}

O Programa de Manejo Diferenciado e Reciclagem de Resíduos tinha como objetivos:

- Eliminar pontos clandestinos de deposição de entulhos;

- Garantir maior vida útil ao aterro sanitário;

- Gerar material de construção alternativo a baixo custo para ser utilizado em substituição a materiais convencionais em uso;

- Contar com a participação da população na entrega de entulho nas unidades de recebimento apropriadas.

- Solucionar o problema dos pequenos geradores pela distribuição, no município, de pontos de entrega voluntária de entulho;

Percebe-se que, embora tenha sido dado um grande avanço com a facilitação de locais para entrega de resíduos, novos pontos de deposição continuaram a ocorrer. Os locais autorizados para deposição de inertes transformaram-se em um novo desafio a ser enfrentado, visto a escassez de tais áreas no município e a impossibilidade de se utilizar o aterro sanitário, que será desativado ainda em 2007.

Os materiais alternativos ainda enfrentam resistência por parte dos construtores e há necessidade de novas pesquisas e um trabalho de conscientização e esclarecimentos para sua inserção no mercado. De acordo com John e Agopyan (2000), existem várias barreiras a serem vencidas para a introdução de novos produtos contendo resíduos: legais/ regulamentares, educação e informação, tecnológicas, econômicas e geográficas e de mercado.

As pequenas construtoras ainda não se adequaram à Resolução Conama 307/02 implantando Programas de Gerenciamento de Resíduos, o que dificulta a segregação e posterior reciclagem do material.

Algumas URPVs não têm espaço suficiente para triagem do material recebido, que também não chega separado e acaba sendo encaminhado para o aterro sanitário. Mesmo o material coletado por empresas particulares muitas vezes não vem segregado, o que dificulta também a reciclagem. De acordo com a entrevista na SLU, duas empresas particulares já perceberam o potencial econômico desses resíduos e fazem primeiro sua segregação, depositando o material para ser reciclado nas Unidades de Reciclagem, vendendo papéis, vidros, plásticos e metais e só depois depositando o material no aterro.

A dificuldade de fiscalização foi outro ponto apontado pela SLU como desafio a ser vencido para uma melhor gestão dos resíduos de construção. As deposições clandestinas ocorrem, em geral, à noite ou nos finais de semana, quando não há fiscalização. Além disso, o setor responsável pela fiscalização na SLU está descentralizado e, muitas vezes, as prioridades de fiscalização nas regionais não são as deposições clandestinas.

O elevado número de construções sendo erguidas sem a aprovação da Prefeitura foi outro fator citado como desafio a ser vencido, já que muitas vezes esses resíduos também são depositados de forma clandestina, sendo necessário, portanto (e como já citado pelo IBAM, 2001) “[...] o envolvimento de diferentes órgãos da administração pública e da sociedade civil com o propósito de realizar a limpeza urbana". Caso todos os órgãos da administração não estejam empenhados em alcançar objetivos comuns, o gerenciamento de resíduos pode não atingir os níveis desejados.

Entre os fatores a serem considerados ao se desenvolver um programa de gerenciamento de resíduos, a caracterização da quantidade e composição de resíduos é de fundamental importância 
(Epa, 1995). Após 14 anos de implantação do modelo de gestão de resíduos de construção civil em Belo Horizonte, essa caracterização não foi implementada.

A caracterização dos resíduos poderia servir de ferramenta para pressionar (ou convencer) os geradores da necessidade de redução e segregação de resíduos.

\section{CONSIDERAÇÃOES FINAIS}

Esse estudo exploratório sobre o modelo de gestão de resíduos de construção adotado pela Prefeitura de Belo Horizonte, desde 1993, se destaca pelas seguintes conquistas: facilitou o descarte, implantou usinas de reciclagem, incorporou os carroceiros como parceiros no programa de coleta de entulhos, disponibilizou o espaço físico para a implantação da fábrica Ecoblocos; e recuperou áreas degradadas, além de ter se revelado um eficaz instrumental para controle dos resíduos de forma sustentável.

Porém, alguns aspectos foram identificados como necessários para um gerenciamento mais adequado do projeto: uma fiscalização mais eficaz ou novas formas de fiscalização podem reduzir o número de deposições clandestinas; um contínuo investimento na educação da população para tomada de consciência; a adoção de novas diretrizes que também objetivem a minimização dos resíduos, o que implicaria na diminuição de resíduo entrando no sistema de limpeza urbana; e a caracterização dos resíduos de construção do município.

Há a necessidade de maior fiscalização nas empresas construtoras, de forma a conscientizálas da necessidade de se adaptarem nesse novo modelo de responsabilidade e competitividade.

A taxação de resíduo gerada precisaria ser estudada de forma a não acarretar o efeito perverso de desestimular a entrega correta dos resíduos.

Esses aspectos, muitas vezes, transcendem as atribuições do órgão responsável pela limpeza urbana, demandando ações de outros órgãos administrativos. Muitos desafios até o momento foram vencidos por meio de convênios, parcerias e investimento em educação para a conscientização e sensibilização dos geradores, que são objetos de estudos relevantes para futuras pesquisas sobre o tema.

\section{REFERÊNCIAS}

Amaral, V. G. (2006) Política e resolução de conflitos urbanos: o caso do aterro sanitário de Belo Horizonte/MG. Dissertação de Mestrado. FAFICH/UFMG.

Ângulo, S. C., Zordan, S. E., John,V. M.(2001) Desenvolvimento sustentável e a reciclagem de resíduos na construção civil. In: IV Seminário Desenvolvimento Sustentável e Reciclagem na Construção. São Paulo, 2001.

Barros, R., Moller, L. M.(1995) Limpeza pública in Manual de Saneamento e Meio Ambiente para os Municípios. V. 2 - Saneamento. BH/DESA/GTZ.

Brollo, M. J., Silva, M. M. (2001) Política e gestão ambiental em resíduos sólidos. Revisão e análise sobre a atual situação Brasil. In: Congresso Brasileiro de Engenharia Sanitária e Ambiental, 21. João Pessoa/PB.

Epa (1995) Decision Marker's Guide to Solid Waste Management. - V. II, Cap. 3

Fiúza, S. M. (2001) Projeto para unidades de recolhimento de entulho da construção civil, Congresso Brasileiro de Engenharia Sanitária e Ambiental, 21. João Pessoa/PB. 
Ibam/Sedu (2001) Manual de gerenciamento integrado de resíduos sólidos. Rio de Janeiro.

John, V. M., Agopyan, V.(2000) - Reciclagem de Resíduos da Construção. In: Seminário de Resíduos Sólidos e Domiciliares. São Paulo, 2000.

Lima, E. S.; Chenna, S. I. (2000) Reciclagem de entulho, Viçosa, CPT.

Pinto, T. P.(1999) Metodologia para a gestão diferenciada de resíduos de construção urbana. Tese de doutorado. São Paulo/USP.

Relatório SLU “Gerenciamento dos Resíduos Sólidos Urbanos em Belo Horizonte: um enfoque com base na realidade ambiental e sócio-econômica", s.d.

Relatórios de Atividades da Limpeza Urbana, SLU, de 1993 a 2007

Silva, P. J., Brito, M. J. (2006) Práticas de gestão de resíduos da construção civil: uma análise da inclusão social de carroceiros social de carroceiros e cidadãos desempregados, Gestão \& Produção.

Data do recebimento do artigo: 22/12/2010

Data do aceite de publicação: 23/02/2012 